\title{
Adubação mineral na fase produtiva da palma óleo (elaeis guineenses jacq) cultivado na região Amazônica
}

A pesar da relevância socioeconomica da palma de óleo (Elaeis guineenses, Jacq) para a região norte do país, ainda são escassas as informações de adubação da cultura. $O$ objetivo dest pesquisa foi avaliar os efeitos da adubação com nitrogênio (N), fósforo (P), potássio (K) e magnésio (Mg) na produção e estado nutricional de plantas de palma de óleo de diferentes idades. Utilizou-se o delineamento experimental em blocos ao acaso com três repetições em esquema fatorial $3 \times 3 \times 3 \times 2$, sendo três níveis de $P$, três de $K$, três $M g$ e dois níveis de $\mathrm{N}$ em parcelas subdivididas. Foi efetuada adubação na área experimental, com $300 \mathrm{~kg}$ ha-1 de fosfino parcialmente acidulado e uma aplicação de $42,9 \mathrm{~kg}$ ha-1 de. As fontes de N, P, K e Mg utilizadas foram, respectivamente, uréia, fosfino, cloreto de potássio e sulfato de magnésio. Constatou-se que a adubação nitrogenada tende a proporcionar respostas em produção imediatas nas plantas jovens ( 5 a 6 anos). Para a adubação fosfatada, houve maior influência na produção nos três últimos anos, notadamente a partir dos quatros anos de idade das plantas. Houve influência da adubação magnesiana logo nos primeiros anos de produção da palma de óleo, apresentando crescimento linear positivo nas plantas com idade acima de seis anos. Ouanto aos teores foliares, em função das aplicações de N, P, K e Mg, foi observado que mesmo na ausência da adubação nitrogenada o teor de N mostrou-se dentro da faixa adequada (24 a $30 \mathrm{~g}$ kg-1). A adubação fosfatada e magnsesiana não influenciaram os teores foliares de N. Com o aumento das doses de fosfino ocorreu melhoria significativa na nutrição da palma de óleo, sendo que a adubação nitrogenada não alterou os teores foliares de P. $\mathrm{O}$ teor foliar de $\mathrm{K}$ nas plantas que receberam adubação nitrogenada apresentou declínio significativo a partir do envelhecimento das plantas. As adubações nitrogenada e fosfatada favoreceram o teor foliar de $\mathrm{N}$ em plantas jovens. A adubação potássica (1,5 kg planta-1) otimizou o teor foliar de $\mathrm{P}$ nas plantas mais velhas. 0 teo foliar de $\mathrm{Mg}$ em plantas de seis anos encontra-se correlacionado com aplicação de $\mathrm{Mg}, \mathrm{N}$ e P. Plantas jovens (dois e quatro anos) apresentaram teor foliar de Ca com forte correlação com a aplicação de cloreto de potássio. A adubação fosfatada elevou o teor foliar de $\mathrm{Cl}$ e a adubação com cloreto de potássio diminuiu os teores foliares de $\mathrm{B}$.

Palavras-chave: Sustentabilidade; Meio Ambiente; Fertilidade; Nutrição de plantas.

\section{Mineral fertilization in the palma oil (elaeis guineenses jacq) production phase cultivated in the Amazon region}

\begin{abstract}
Despite the socioeconomic relevance of oil palm (Elaeis Guineans, Jacq) for the northern region of the country, there is still little information on crop fertilization. The objective of this research was to evaluate the effects of nitrogen $(\mathrm{N})$, phosphorus $(\mathrm{P})$, potassium $(\mathrm{K})$ and magnesium $(\mathrm{Mg})$ fertilization on the production and nutritional status of oil palm plants of different ages. A randomized complete block design with three replications in a $3 \times 3 \times 3 \times 2$ factorial scheme was used, with three levels of $P$, three of $K$, three $\mathrm{Mg}$ and two levels of $\mathrm{N}$ in subdivided plots. experimental area with $300 \mathrm{~kg}$ ha -1 of partially acidulated phosphine and an application of $42.9 \mathrm{~kg}$ ha -1 of. The sources of $\mathrm{N}, \mathrm{P}, \mathrm{K}$ and $\mathrm{Mg}$ used were, respectively, urea, phosphine, potassium chloride and magnesium sulfate. Nitrogen fertilization tended to provide immediate yield responses in young plants ( 5 to 6 years). For phosphate fertilization, there was greater influence on yield in the last three years, notably from the four years of age of the plants. Magnesian fertilization was influenced in the early years of oil palm production, showing positive linear growth in plants older than six years. As for leaf contents, as a function of $\mathrm{N}, \mathrm{P}, \mathrm{K}$ and $\mathrm{Mg}$ applications, it was observed that even in the absence of nitrogen fertilization the $\mathrm{N}$ content was within the appropriate range (24 to $30 \mathrm{~g} \mathrm{~kg}-1$ ). Phosphate and magnesian fertilization did not influence $\mathrm{N}$ leaf contents. Increasing phosphine rates significantly improved oil palm nutrition, and nitrogen fertilization did not affect $\mathrm{P}$. leaf contents. K leaf content in plants that received nitrogen fertilization showed significant decline from the aging of the plants. Nitrogen and phosphate fertilization favored leaf $\mathrm{N}$ content in young plants. Potassium fertilization (1.5 kg plant-1) optimized P leaf content in older plants. Leaf $\mathrm{Mg}$ content in six-year-old plants correlated with $\mathrm{Mg}$ $\mathrm{N}$ and $\mathrm{P}$ application. Young plants (two and four years old) showed Ca leaf content strongly correlated with potassium chloride application. Phosphate fertilization increased $\mathrm{Cl}$ leaf content and potassium chloride fertilization decreased B. leaf content.
\end{abstract}

Keywords: Sustainability; Environment; Fertility; Plant Nutrition.

Ismael de Jesus Matos Viégas (iD

Universidade Federal Rural da Amazônia, Brasil http://lattes.cnpq.br/5645151005844327

http://orcid.org/0000-0001-7212-1977

matosviegas@hotmail.com

Mauro Jorge de Oliveira Pimentel

Universidade Federal Rural da Amazônia, Brasil

mauro.pimentel102521@gmail.com

Jessivaldo Rodrigues Galvão (id

Universidade Federal Rural da Amazônia, Brasil

http://lattes.cnpq.br/0013591065769741

http://orcid.org/0000-0003-4242-6555

jessigalvao50@gmail.com
Diocléa Almeida Seabra Silva (1D)

Universidade Federal Rural da Amazônia, Brasil http://lattes.cnpq.br/8554224619653187

http://orcid.org/0000-0002-1451-0285

dioclea.seabra@ufra.edu.br

Eric Victor de Oliveira Ferreira

Universidade Federal Rural da Amazônia, Brasil

http://lattes.cnpq.br/8711223656250765

ericsolos@yahoo.com.br

Mário Lopes da Silva Junior (ii

Universidade Federal Rural da Amazônia, Brasi

http://lattes.cnpq.br/2220699289355930

http://orcid.org/0000-0001-9772-1290

mario.silva@ufra.edu.br
Tiago Kesajiro Moraes Yakuwa

Universidade Federal Rural da Amazônia, Brasil http://lattes.cnpq.br/7558554557581020 http://orcid.org/0000-0001-6412-9303 tiagokmyakuwa@gmail.com

Silvia Kalini dos Santos de Lima Universidade Federal Rural da Amazônia, Brasil http://lattes.cnpq.br/9901888136752818 kaliny140@gmail.com

\section{Referencing this:}

VIEGAS, I. J. M.; PIMENTEL, M. J. O.; GALVÃO, J. R.; SILVA, D. A. S.; FERREIRA, E. V. O.; SILVA JÚNIOR, M. L.; YAKUWA, T. K. M.; LIMA, S. K. S.. Adubação mineral na fase produtiva da palma óleo (elaeis guineenses jacq) cultivado na região Amazônica. Revista Ibero Americana de Ciências Ambientais, v.10, n.6, p.274-286, 2019. DOI: http://doi.org/10.6008/CBPC2179-6858.2019.006.0024 


\section{INTRODUÇÃO}

A palma de óleo (Elaeis guineensis, Jacq.) é uma palmeira de origem africana, pertencente à família Arecacea, que no Brasil foi introduzida a partir do século XV pelo intenso tráfico e comercialização de escravos, dando origem ao crescimento subespontâneo da palma de óleo no litoral Baiano. A produção mundial de óleo de palma é de 35 \% seguido pela soja, colza e girassol. A Indonésia com 10 milhões de hectares e a Malásia com quatro milhões apresentam as maiores áreas plantadas com palma de óleo, sendo responsáveis por 66 milhões de toneladas de óleo comercializadas ocupando o primeiro lugar na produção mundial desse produto. O Brasil está na 12a colocação produzindo 340 mil toneladas e importa praticamente a mesma quantidade para atender à sua demanda. A dendeicultura desponta como uma atividade de multiuso e economicamente viável nos países em desenvolvimento (PHOSRI et al., 2010). Na região Norte do Brasil surge como base para promoção do desenvolvimento econômico, social e promoção da biodiversidade (SILVA et al., 2011).

A palma de óleo, em função da sua grande capacidade produtiva, apresenta elevada extração de nutrientes (GAMARRA, 2014). Entretanto, a demanda nutricional desta cultura possui elevada variação dependendo basicamente do tipo de material vegetal plantado, clima, solo, espaçamento, planta de cobertura, fatores ambientais e níveis de adubação adotados (BAKAR et al., 2011). Conhecer a concentração e o acúmulo dos nutrientes nos diversos órgãos da planta em sucessivos estádios de desenvolvimento é condição essencial para se entender as origens dos problemas nutricionais, e viabilizar recomendações de reposição dos nutrientes, mantendo o potencial produtivo da cultura. Estudos relacionados à absorção e ao transporte de macro e micronutrientes nas plantas de palma de óleo demonstram grande variação nos seus teores foliares (GAMARRA, 2014).

A diagnose foliar no processo de avaliação nutricional das plantas permite estabelecer faixas de teor ótimo e, ou, níveis críticos foliares que são essenciais no planejamento do processo (UEXKULL et al., 1991). Guzmán (2014) constatou, para condições da Amazônia brasileira, diferenças notórias em faixas de referência dos teores foliares de nutrientes para a palma de óleo com as verificadas na literatura. Tal fato indica a necessidade de mais estudos relacionados ao tema, principalmente em nível local. Apesar da exigência nutricional da palma de óleo durante os três primeiros anos de vida ser considerada relativamente pequena, há necessidade de boa nutrição nesta fase da cultura.

As pesquisas com nutrição e adubação da palma de óleo na Amazônia brasileira foram iniciadas na década de sessenta do século passado no município de Benevides, estado do Pará. Os resultados obtidos nessas pesquisas foram de grande importância para as primeiras indicações de adubação para a cultura da palma de óleo. Na década de 80, quando ocorreu a expansão do cultivo da palma de óleo para outros municípios do Estado, foram desenvolvidas mais três pesquisas e os seus resultados são as bases para as recomendações atuais de adubação (VIÉGAS et al., 2000). A partir dessa época, poucos trabalhos de pesquisa deram suporte às recomendações, indicando a necessidade de atualizações das mesmas.

Neste sentido, é essencial pensar na adubação dentro do sistema de produção, pois embora as 
recomendações de corretivos e fertilizantes estejam sendo consideradas satisfatórias em aumentar a eficácia do sistema produtivo, ainda devem ser executados ajustes para aperfeiçoá-las. Desta forma, a pesquisa teve como objetivo avaliar os efeitos produzidos pela adubação nitrogenada, fosfatada, potássica e magnesiana sobre a produção e estado nutricional da palma de óleo.

\section{MATERIAIS E MÉTODOS}

O experimento foi instalado na propriedade da AGROPALMA localizada no município de Tailândia, às

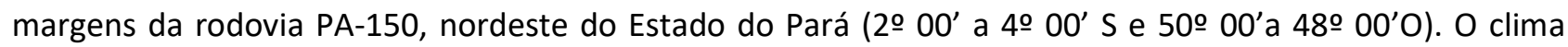
caracteriza-se como tropical chuvoso sem variação térmica estacional e apresenta elevado índice pluviométrico anual. A distribuição das chuvas é caracterizada no período chuvoso (dezembro a maio) e menos chuvoso (junho a novembro). Na região há predomínio de Latossolo Amarelo distrófico, classe de baixa fertilidade química natural.

Antes da instalação do experimento, com auxílio de um trado, foram retiradas aleatoriamente amostras compostas de quatro amostras simples de solo nas profundidades de 0 a 30 e $30 \mathrm{a} 50 \mathrm{~cm}$. Essas amostras foram submetidas à análise química e granulométrica (Tabela 1) no laboratório do ex- Institut de Recherches pour les Huiles et Oléagineux - IRHO.

Tabela 1: Análise química e granulométrica do solo da área experimental nas profundidades de 0-30 e 30-50 cm.

\begin{tabular}{|l|l|l|}
\hline Atributos & $\begin{array}{l}\text { Valores médios } \\
(0-30 \mathrm{~cm})\end{array}$ & $\begin{array}{l}\text { Valores médios } \\
(30-50 \mathrm{~cm})\end{array}$ \\
\hline $\mathrm{pH}\left(\mathrm{H}_{2} \mathrm{O}\right)$ & 5,2 & 4,8 \\
\hline $\mathrm{K}^{+*}\left(\mathrm{cmol}_{\mathrm{c}} \mathrm{dm}^{-3}\right)$ & 0,04 & 0,04 \\
\hline $\mathrm{Ca}^{+2 *}\left(\mathrm{cmol}_{c} \mathrm{dm}^{-3}\right)$ & 2,4 & 0,17 \\
\hline $\mathrm{Mg}^{+2 *}\left(\mathrm{cmol}_{\mathrm{c}} \mathrm{dm}^{-3}\right)$ & 0,50 & 0,20 \\
\hline $\mathrm{Al}^{+3}\left(\mathrm{cmol}_{\mathrm{c}} \mathrm{dm}^{-3}\right)$ & 0,02 & 0,53 \\
\hline Fósforo total$\left(\mathrm{mg} \mathrm{kg}^{-1}\right)$ & 89 & 89 \\
\hline Fósforo assimilável* $(\mathrm{OLSEN})\left(\mathrm{g} \mathrm{kg}^{-1}\right)$ & 12 & 12,5 \\
\hline Matéria orgânica $\left(\mathrm{g} \mathrm{kg}^{-1}\right)^{* *}$ & 6,4 & 6,9 \\
\hline Areia grossa $\left(\mathrm{g} \mathrm{kg}^{-1}\right)$ & 260 & 300 \\
\hline Areia fina $\left(\mathrm{g} \mathrm{kg}^{-1}\right)$ & 350 & 330 \\
\hline Silte $\left(\mathrm{g} \mathrm{kg}^{-1}\right)$ & 40 & 50 \\
\hline Argila $\left(\mathrm{g} \mathrm{kg}^{-1}\right)$ & 340 & 300 \\
\hline
\end{tabular}

* extraídos com resina trocadora de íons; ${ }^{* *}$ método colorimétrico

O preparo da área foi realizado utilizando desmatamento manual e queima. Os enleiramentos foram mecanizados de forma a padronizar leiras para cada seis linhas plantadas. Para cobertura inicial do solo foi utilizada leguminosa Pueraria phaseoloides. O material genético da palma de óleo utilizada foi proveniente da estação de pesquisa de La Mé do Institut de Recherches pour les Huiles et Oléagineux, sendo constituído pelos híbridos DELI x La Mé. A escolha deu-se a partir de bons resultados no rendimento em óleo por hectare e baixa taxa de crescimento em altura das plantas. As mudas foram submetidas a um pré-viveiro ( 5 a 6 meses) e um período de viveiro, que se estendeu por nove meses. O plantio ocorreu na forma de triângulo equilátero em quincôncio de $9 \mathrm{~m}$ entre plantas e 7,8 $\mathrm{m}$ entre linhas, com uma população de aproximadamente 143 plantas/ha.

Utilizou-se o delineamento experimental em blocos casualizados, com três repetições em esquema fatorial $3 \times 3 \times 3 \times 2$, sendo três níveis de fósforo $(P)$, três de potássio $(K)$, três de magnésio $(\mathrm{Mg})$, além de dois 
níveis de nitrogênio (N) em parcelas subdivididas (27 parcelas principais e 54 subparcelas). Cada bloco foi composto por nove parcelas principais e cada subparcela foi constituída de 36 plantas (6 linhas de 6 plantas), sendo 16 úteis. Os tratamentos com as doses de $\mathrm{P}, \mathrm{K}$ e $\mathrm{Mg}$ relativos aos fatores principais foram 3 níveis de $P=1$, 2 e 3 e para $\mathrm{K}$ e $\mathrm{Mg}=0$, 1 e 2 (Tabela 2). A pesquisa com nitrogênio foi aplicada na subparcela (presença e ausência).

Devido à baixa disponibilidade de fósforo foi inicialmente efetuada no terceiro ano de idade, uma adubação superficial a lanço em toda a área experimental, com $300 \mathrm{~kg} \mathrm{ha}^{-1}$ de fosfino parcialmente acidulado (33\% de $\mathrm{P}_{2} \mathrm{O}_{5}$ total) e uma aplicação de $42 \mathrm{~kg} \mathrm{ha}^{-1}$ de ureia (45 \% de $\mathrm{N}$ ) no coroamento das palmeiras. As doses dos fertilizantes nas adubações posteriores (Tabela 2) foram distribuídas uniformemente sobre a superfície do solo em um círculo a partir do estipe das plantas. As fontes de $\mathrm{N}, \mathrm{P}, \mathrm{K}$ e Mg utilizadas foram: ureia ( $45 \%$ de $\mathrm{N}$ ), fosfino ( $33 \%$ de $\mathrm{P}_{2} \mathrm{O}_{5}$ e $42 \%$ de $\mathrm{CaO}$ ), cloreto de potássio (60 \% de $\mathrm{K}_{2} \mathrm{O}$ e $45 \%$ de $\mathrm{Cl}$ ) e sulfato de magnésio ( $18 \%$ de $\mathrm{MgO}$ e $13 \%$ de S).

Tabela 2: Fontes, épocas de aplicação e doses de fertilizantes ( $\mathrm{g} /$ planta) utilizadas no experimento.

\begin{tabular}{|c|c|c|c|c|c|c|c|c|c|c|c|c|c|c|}
\hline \multirow[t]{2}{*}{ Fontes } & \multirow[t]{2}{*}{ Niveis } & $\mathrm{A} 0$ & A1 & $\mathrm{A} 2$ & A3 & A4 & A5 & A6 & A7 & A8 & A9 & A10 & A11 & A12 \\
\hline & & Set* & Maio & Maio & Maio & Jun & Maio/Jun & Maio & Jun & Jun & Jul & Maio & Jun & Jun \\
\hline \multirow{3}{*}{$\begin{array}{l}\text { Fosfino** } \\
\text { g/planta }\end{array}$} & 1 & 0 & 0 & 0 & $* * *$ & - & 0 & 0 & 500 & 500 & 500 & 500 & 500 & 500 \\
\hline & 2 & 500 & 500 & 500 & - & - & 500 & 800 & 1250 & 1250 & 1250 & 1250 & 1250 & 1000 \\
\hline & 3 & 1000 & 1000 & 1000 & - & - & 1000 & 1600 & 2000 & 2000 & 2000 & 2000 & 2000 & 1500 \\
\hline \multirow[t]{3}{*}{$\mathrm{KCl}$ g/planta } & 0 & 0 & 0 & 0 & 0 & 0 & 0 & 0 & 0 & 0 & 0 & 0 & 0 & 0 \\
\hline & 1 & 150 & 250 & 500 & 750 & 100 & 1200 & 1500 & 1500 & 1500 & 1600 & 1600 & 500 & 1500 \\
\hline & 2 & 300 & 500 & 1000 & 1500 & 2000 & 2400 & 3000 & 3000 & 3000 & 3200 & 3200 & 3000 & 3000 \\
\hline \multirow{3}{*}{$\begin{array}{l}\text { Sulfato de } \\
\text { Mg g/planta }\end{array}$} & 0 & 0 & 0 & 0 & 0 & 0 & 0 & 0 & 0 & 0 & 0 & 0 & 0 & 0 \\
\hline & 1 & 150 & 250 & 500 & 500 & 500 & 500 & 700 & 700 & 700 & 700 & 700 & 700 & 500 \\
\hline & 2 & 300 & 500 & 1000 & 1000 & 1000 & 1000 & 1400 & 1400 & 1400 & 1400 & 1400 & 1400 & 1000 \\
\hline \multirow{2}{*}{$\begin{array}{l}\text { Úreia } \\
\text { g/planta }\end{array}$} & 0 & 0 & 0 & 0 & 0 & 0 & 0 & 0 & 0 & 0 & 0 & 0 & 0 & 0 \\
\hline & 1 & 150 & 300 & 500 & 500 & 500 & 1200 & 1000 & 1000 & 1000 & 1000 & 1000 & 1000 & 500 \\
\hline $\begin{array}{l}\text { Borax } \\
\text { g/planta }\end{array}$ & - & 100 & 100 & 100 & 100 & 100 & 100 & 100 & 100 & 100 & 100 & 100 & 100 & 100 \\
\hline
\end{tabular}

$\mathrm{A}_{0}=$ ano de plantio; $\mathrm{A} 1=$ primeiro ano ... A12 = ano; * Mais aplicação de 2100 e $4200 \mathrm{~kg} / \mathrm{ha}$ de fosfino $\left(33 \% \mathrm{P}_{2} \mathrm{O}_{5}\right)$ respectivamente, nos níveis $\mathrm{P}_{2}$ e $\mathrm{P}_{3}$; ${ }^{* *}$ Fosfino com $33 \% \mathrm{P}_{2} \mathrm{O}_{5}$ e $42 \%$ de $\mathrm{CaO}$.; *** Não foi aplicado adubo fosfatado.

A resposta à aplicação dos tratamentos em termos de produção foi avaliada pela contagem do número médio de cachos por planta (NMCP), peso médio dos cachos (kg planta-1 ${ }^{-1}$ e a produção (t de cachos/ha/ano). Na amostragem foliar, a coleta dos folíolos foi realizada em todas as plantas úteis de cada subparcela. Nas palmeiras com até dois anos se coletou os folíolos da folha 9, e a partir do terceiro ano os da folha 17, seguindo as recomendações (VIÉGA et al., 2000). As análises foliares dos teores de N, P, K, Ca, Mg, $\mathrm{S}, \mathrm{B}$ e Cl foram realizadas no laboratório de plantas do ex-Institut de Recherches por les Huiles et Oléagineaux - IRHO, com exceção do décimo segundo ano que foram efetuadas no laboratório do Departamento de Ciência do Solo da Universidade Federal de Lavras - UFLA, seguindo-se os métodos descritos (SARRUGE et al., 1974). A determinação do teor de Cl pela Embrapa, Centro de Pesquisa Agroflorestal da Amazônia Ocidental, pela titulação com nitrato de prata, segundo método indicado pelo Institut de Recherches pour les Huiles et Oléagineux (1989).

Os resultados obtidos no experimento foram submetidos à análise de variância $(p<0,05)$ e as médias dos tratamentos com relação à aplicação e não aplicação de $\mathrm{N}$ foram comparadas pelo teste de Tukey ( $p<$ 0,05). $\mathrm{O}$ efeito das doses de $\mathrm{P}, \mathrm{K}$ e Mg foram avaliados por regressão, estimando-se as curvas de resposta às 
suas doses, bem como as suas interações. A estrutura de variância e covariância do vetor aleatório, composto de $p$-variáveis aleatórias do experimento, foi sumarizada e avaliada a partir da análise multivariada de componentes principais - ACP.

\section{RESULTADOS E DISCUSSÃO}

Os resultados da adubação nitrogenada nas variáveis de produção da palma de óleo, número médio de cachos/planta e a produção total (t de cachos/ha/ano) durante nove anos de produção do plantio da palma de óleo se encontram na Tabela 3. A produção total a partir da adubação nitrogenada $\left(\mathrm{N}_{1}\right)$ tende a apresentar respostas imediatas nas plantas jovens ( 5 a 6 anos), porém sem efeito significativo em idades intermediárias (6 a 7 anos). Por outro lado, com o aumento da idade das plantas a partir dos oito anos a produção total flutua entre 10 a $20 \mathrm{t}$ de cachos/ha/ano, ou seja, a produção se eleva à medida em que as plantas ficam mais velhas não apresentando diferenças significativas entre os níveis de adubação nitrogenada utilizada (Tabela 4).

A não resposta à aplicação da adubação nitrogenada é explicada pelo fornecimento de nitrogênio proveniente da cobertura do solo com a leguminosa Pueraria phaseoloides, através da mineralização da matéria orgânica transformando o nitrogênio orgânico em mineral. De acordo com a pesquisa de Perez (1997) na idade de 2 a 8 anos a Pueraria phaseoloides extrai 1237,66 kg/ha de nitrogênio e considerando uma densidade de 143 plantas de palma de óleo se tem 8,65 kg/planta, que corresponde em ureia com 45\% de $\mathrm{N} 19 \mathrm{~kg}$ de ureia que no período de 7 anos da Puerária, corresponde uma média de 2,74 kg de ureia. Aliase a este fato, o preparo da área mecanizada formando empilhamentos com restos de vegetais espaçados de $20 \mathrm{~m}$. Esses empilhamentos com os restos vegetais, principalmente madeiras, através da sua composição, também deve ter contribuído com fornecimento de nitrogênio para as plantas. Em plantação da palma de óleo de 15 anos de idade na Amazônia se verificou que a concentração de $\mathrm{N}$ mineral no solo (até $2 \mathrm{~m}$ de profundidade) foi muito baixa na região mais próxima das plantas indicativo de eficiente absorção de $\mathrm{N}$ pelas palmas (SCHROTH et al., 2000).

A adubação fosfatada $\left(\mathrm{P}_{2}\right.$ e $\left.\mathrm{P}_{3}\right)$ proporcionou maior produção nos três últimos anos, sendo observado a partir do 40 ano uma elevação gradual da produção (Tabela 3). Em plantas com idade entre seis e 10 anos a produção ultrapassa $10 \mathrm{t}$ cachos/ha/ano. Esses resultados indicam efeito da interação entre idade das plantas e a dose aplicada de $\mathrm{P}$, sendo significativo o aumento da produção a partir do 4으 ano de idade das plantas. Embora não tenha havido adubação fosfatada no referido ano, o efeito residual da adubação realizada em toda a área foi suficiente para nutrir a cultura neste período.

Isso demonstra a importância do efeito residual do $\mathrm{P}$, fato que tende a reduzir custos com a aplicação do fertilizante e que deve ser estudado em outras pesquisas com a palma de óleo. Do sétimo ao décimo segundo ano o peso médio de cachos não mostrou diferença significativa com a aplicação do fosfino, ocorrendo uma estabilização do processo produtivo da palma de óleo (t de cachos/ha/ano). A produção média do número de cachos/planta se mostrou significativa em relação ao aumento das doses de $P$, porém foi observada redução com o decorrer dos anos nesta variável. As produções nas maiores doses de $\mathrm{P}\left(\mathrm{P}_{3}\right)$ 
foram superiores às observadas no nível dois de $P\left(P_{2}\right)$ na idade de 4, 6 e 9 anos, não havendo diferença entre as duas doses de $\mathrm{P}$ nos demais anos de avaliação (Tabela 4). Vale ressaltar que com o aumento das doses de fosfino o peso médio de cachos apresentou redução significativa.

A aplicação de P promoveu diferença significativa ao longo dos anos estudados no número médio de cachos, porém com pequena redução em seus valores, fato explicado pelo aumento do peso médio dos cachos $\left(\mathrm{kg} \mathrm{planta}^{-1}\right)$ a partir do quarto ano. As aplicações de cloreto de potássio sobre a produção da palma de óleo do quarto ao oitavo ano não influenciaram no número médio de cachos planta ${ }^{-1}$. Do sétimo ao nono ano, houve redução na produção, o que pode ser explicado pelo aumento no peso médio de cachos (kg plata$\left.{ }^{1}\right)$ da palma de óleo.

A aplicação de $\mathrm{K}$ aumentou o peso médio dos cachos $\left(\mathrm{kg}\right.$ planta $\left.{ }^{-1}\right)$ em todos os anos estudados, enquanto para a produção (t de cachos/ha/ano) o incremento só não ocorreu no quinto ano, o que confirma a necessidade e importância desse nutriente para a palma de óleo (Tabela 3; Tabela 4). A aplicação do cloreto de potássio proporcionou aumento gradual na produção do número de cachos da palma de óleo a partir do quarto ano de idade com leve declínio no 9o ano, voltando a crescer significativamente a partir do 10으 ao 12으 ano (Tabela 4).

A aplicação de sulfato de magnésio em nove anos de observação das colheitas proporcionou influência significativa na produção da palma de óleo (t de cachos/ha/ano) somente no primeiro ano de produção, não ocorrendo do segundo ao oitavo ano, nenhum aumento na produção, apesar do baixo teor de magnésio no solo de acordo com a classificação de Brasil et al. (2010) (Tabela 4). Pacheco et al. (1985) também não obtiveram aumento da produtividade da palma de óleo com o fornecimento de sulfato de magnésio nas condições edafoclimáticas da região de Belém, Estado do Pará, Brasil. Santos (1999) constatou que a produtividade aumentou com o suprimento do fertilizante somente no 11 o e $12^{\circ}$ ano de idade da palma de óleo, com valores de 13.46 e $16.39 \mathrm{t} \mathrm{ha}^{-1}$ de cachos, respectivamente.

Possivelmente, o fornecimento do Mg pela mineralização da matéria orgânica, proveniente principalmente da leguminosa Pueraria phaseoloides utilizada como cobertura do solo em plantios da palma de óleo, disponibilizou a quantidade necessária para a produção da palma de óleo, justificando a não obtenção de resposta para a aplicação de doses de Mg. De acordo com Perez (1997) a Puerária phaseoloides fornece $143.7 \mathrm{~kg} \mathrm{ha}^{-1}$ de $\mathrm{Mg}$ do 2 ㅇ até o 8 o ano de idade, e com uma densidade de 143 plantas ha ${ }^{-1}$ da palma de óleo resultaria no fornecimento de $1.0 \mathrm{~kg}_{\text {planta }}{ }^{-1} \mathrm{ano}^{-1} \mathrm{de} \mathrm{Mg}$. Aumentos na produtividade em plantas da palma de óleo são relatados por Dubos et al. (1999) com a aplicação de Mg na América latina, África e Ásia.

Tabela 3: Efeitos da adubação N, P, K e Mg no número médio de cachos/planta, peso médio dos cachos (kg/planta) e a produção (t de cachos/ha).

\begin{tabular}{|l|l|l|l|l|l|l|l|l|l|l|l|l|}
\hline $\begin{array}{l}\text { Idade } \\
\text { Anos }\end{array}$ & $\begin{array}{l}\text { Anos de } \\
\text { colheitas }\end{array}$ & $\mathrm{N}_{0}$ & $\mathrm{~N}_{1}$ & $\mathrm{P}_{1}$ & $\mathrm{P}_{2}$ & $\mathrm{P}_{3}$ & $\mathrm{~K}_{0}$ & $\mathrm{~K}_{1}$ & $\mathrm{~K}_{2}$ & $\mathrm{Mg}_{0}$ & $\mathrm{Mg}_{1}$ & $\mathrm{Mg}_{2}$ \\
\hline
\end{tabular}




\begin{tabular}{|c|c|c|c|c|c|c|c|c|c|c|c|c|}
\hline 11 & 8 & $8,35 a$ & $8,09 a$ & $8,20 a$ & $8,56 a$ & $7,89 a$ & $6,35 b$ & $9,09 a$ & $9,22 a$ & $8,53 a$ & $8,27 a$ & $7,85 a$ \\
\hline 12 & 9 & $8,45 a$ & $8,31 a$ & $8,52 a$ & $8,70 a$ & $7,92 a$ & $6,01 b$ & $9,46 a$ & $9,67 a$ & $8,87 a$ & $8,26 a$ & $8,02 a$ \\
\hline \multicolumn{13}{|c|}{ Peso médio de cachos (kg/planta) } \\
\hline 4 & 1 & $44,96 a$ & $46,92 a$ & $25,26 c$ & $44,68 b$ & $66,90 a$ & $40,87 b$ & $48,65 a$ & $48,30 a$ & $43,80 b$ & $51,90 a$ & $42,12 b$ \\
\hline 5 & 2 & $45,13 a$ & $47,91 a$ & $31,80 c$ & $48,95 b$ & $58,81 a$ & $42,90 \mathrm{~b}$ & $49,95 a$ & $46,71 a b$ & $49,33 a$ & $45,57 a$ & $44,67 a$ \\
\hline 6 & 3 & $108,34 a$ & $113,96 a$ & $77,32 c$ & $120,38 b$ & $135,75 a$ & $98,03 b$ & $112,20 a$ & $123,22 a$ & $112,42 a$ & $108,96 a$ & $112,07 a$ \\
\hline 7 & 4 & $96,19 a$ & $96,35 a$ & $55,66 b$ & $108,64 a$ & $124,50 a$ & $81,38 b$ & $99,90 a b$ & $107,52 a$ & $97,18 a$ & $95,98 a$ & $95,65 a$ \\
\hline 8 & 5 & $87,85 a$ & $93,93 a$ & $57,99 b$ & $102,22 a$ & $112,47 a$ & $71,75 b$ & $100,16 a$ & $100,77 a$ & $93,42 a$ & $93,62 a$ & $85,63 a$ \\
\hline 9 & 6 & $68,10 a$ & $66,23 a$ & $39,91 c$ & $75,12 b$ & $86,48 a$ & $50,10 b$ & $71,60 a$ & $79,80 a$ & $67,91 a$ & $67,19 a$ & $66,40 a$ \\
\hline 10 & 7 & $84,03 a$ & $82,72 a$ & $59,11 b$ & $95,25 a$ & $95,76 a$ & $55,76 b$ & $93,74 a$ & $100,61 a$ & $86,14 a$ & $82,52 a$ & $81,46 a$ \\
\hline 11 & 8 & $101,35 a$ & $100,73 a$ & $85,04 b$ & $110,85 a$ & $107,23 a b$ & $61,54 b$ & $119,09 a$ & $122,48 a$ & $102,04 a$ & $101,16 a$ & $99,92 a$ \\
\hline 12 & 9 & $98,83 a$ & $103,13 a$ & $93,74 a$ & $111,98 a$ & $97,23 a$ & $57,93 b$ & $123,56 a$ & $121,46 a$ & $96,78 a$ & $103,65 a$ & $102,51 a$ \\
\hline \multicolumn{13}{|c|}{ Produção (t de cachos/ha/ano) } \\
\hline 4 & 1 & $6,07 a$ & $6,80 a$ & $3,54 c$ & $6,24 b$ & $9,03 a$ & $5,51 b$ & $6,78 a$ & $6,52 a$ & $6,13 a b$ & $7,00 a$ & $5,68 b$ \\
\hline 5 & 2 & $5,58 a$ & $6,46 a$ & $4,29 b$ & 6,60a & $7,43 a$ & $5,79 a$ & $6,74 a$ & $5,80 a$ & $6,65 a$ & $5,65 a$ & $6,02 a$ \\
\hline 6 & 3 & $14,33 a$ & $15,38 a$ & $10,00 c$ & $16,25 b$ & $18,32 \mathrm{a}$ & $13,23 b$ & $14,71 \mathrm{ab}$ & $16,63 a$ & $15,17 a$ & $14,27 a$ & $15,13 a$ \\
\hline 7 & 4 & $12,98 a$ & $13,00 a$ & $7,51 b$ & $14,65 a$ & $16,80 a$ & $10,98 b$ & $13,47 a b$ & $14,51 a$ & $13,11 a$ & $12,95 a$ & $12,91 \mathrm{a}$ \\
\hline 8 & 5 & $11,86 a$ & $12,67 a$ & $7,82 b$ & $13,80 a$ & $15,18 a$ & $9,69 \mathrm{~b}$ & $13,51 a$ & $13,60 a$ & $12,61 a$ & $12,63 a$ & $11,55 a$ \\
\hline 9 & 6 & $9,19 a$ & $8,94 a$ & $5,38 c$ & $10,14 b$ & $11,67 a$ & $6,76 b$ & $9,66 a$ & $10,77 a$ & $9,16 a$ & $9,07 a$ & $8,96 a$ \\
\hline 10 & 7 & $11,34 a$ & $11,16 a$ & $7,98 b$ & $12,86 a$ & $12,92 a$ & $7,53 b$ & $12,65 a$ & $13,58 a$ & $11,62 a$ & $11,14 a$ & $11,00 a$ \\
\hline 11 & 8 & $13,68 a$ & $13,96 a$ & $12,03 b$ & $14,94 a$ & $14,48 a$ & $8,30 \mathrm{~b}$ & $16,63 a$ & $16,53 a$ & $13,76 a$ & $13,65 a$ & $14,05 a$ \\
\hline 12 & 9 & $14,06 a$ & $13,92 a$ & $12,65 b$ & $15,11 a$ & $14,21 \mathrm{ab}$ & $7,81 \mathrm{~b}$ & $16,68 a$ & $17,48 a$ & $14,15 a$ & $13,99 a$ & $13,83 a$ \\
\hline
\end{tabular}

Tabela 4: Efeito dos níveis de adubação com N, P, K e Mg nas respostas em produtividade na palma de óleo (t de cachos/ ha/ano).

\begin{tabular}{|l|l|l|l|l|l|l|l|l|l|l|l|}
\hline Idade Anos & $\mathrm{N}_{0}{ }^{1}$ & $\mathrm{~N}_{1}$ & $\mathrm{P}_{1}{ }^{2}$ & $\mathrm{P}_{2}$ & $\mathrm{P}_{3}$ & $\mathrm{~K}_{0}{ }^{3}$ & $\mathrm{~K}_{1}$ & $\mathrm{~K}_{2}$ & $\mathrm{Mg}_{0}{ }^{4}$ & $\mathrm{Mg}_{1}$ & $\mathrm{Mg}_{2}$ \\
\hline 4 & $6,1 \mathrm{a}$ & $6,8 \mathrm{a}$ & $3,5 \mathrm{c}$ & $6,2 \mathrm{~b}$ & $9,0 \mathrm{a}$ & $5,5 \mathrm{~b}$ & $6,78 \mathrm{a}$ & $6,5 \mathrm{a}$ & $6,1 \mathrm{ab}$ & $7,0 \mathrm{a}$ & $5,7 \mathrm{~b}$ \\
\hline 5 & $5,6 \mathrm{a}$ & $6,5 \mathrm{a}$ & $4,3 \mathrm{~b}$ & $6,6 \mathrm{a}$ & $7,4 \mathrm{a}$ & $5,8 \mathrm{a}$ & $6,74 \mathrm{a}$ & $5,8 \mathrm{a}$ & $6,7 \mathrm{a}$ & $5,7 \mathrm{a}$ & $6,0 \mathrm{a}$ \\
\hline 6 & $14,3 \mathrm{a}$ & $15,4 \mathrm{a}$ & $10,0 \mathrm{c}$ & $16,3 \mathrm{~b}$ & $18,3 \mathrm{a}$ & $13,3 \mathrm{~b}$ & $14,71 \mathrm{ab}$ & $16,6 \mathrm{a}$ & $15,2 \mathrm{a}$ & $14,3 \mathrm{a}$ & $15,0 \mathrm{a}$ \\
\hline 7 & $13,0 \mathrm{a}$ & $13,0 \mathrm{a}$ & $7,51 \mathrm{~b}$ & $14,6 \mathrm{a}$ & $16,8 \mathrm{a}$ & $11,0 \mathrm{~b}$ & $13,47 \mathrm{ab}$ & $14,5 \mathrm{a}$ & $13,1 \mathrm{a}$ & $13,0 \mathrm{a}$ & $12,9 \mathrm{a}$ \\
\hline 8 & $11,9 \mathrm{a}$ & $12,7 \mathrm{a}$ & $7,8 \mathrm{~b}$ & $13,8 \mathrm{a}$ & $15,2 \mathrm{a}$ & $9,7 \mathrm{~b}$ & $13,51 \mathrm{a}$ & $13,6 \mathrm{a}$ & $12,6 \mathrm{a}$ & $12,7 \mathrm{a}$ & $11,6 \mathrm{a}$ \\
\hline 9 & $9,2 \mathrm{a}$ & $8,9 \mathrm{a}$ & $5,4 \mathrm{c}$ & $10,1 \mathrm{~b}$ & $11,7 \mathrm{a}$ & $6,8 \mathrm{~b}$ & $9,66 \mathrm{a}$ & $10,8 \mathrm{a}$ & $9,2 \mathrm{a}$ & $9,1 \mathrm{a}$ & $9,0 \mathrm{a}$ \\
\hline 10 & $11,4 \mathrm{a}$ & $11,2 \mathrm{a}$ & $8,0 \mathrm{~b}$ & $12,9 \mathrm{a}$ & $12,9 \mathrm{a}$ & $7,5 \mathrm{~b}$ & $12,65 \mathrm{a}$ & $13,6 \mathrm{a}$ & $11,6 \mathrm{a}$ & $11,1 \mathrm{a}$ & $11,0 \mathrm{a}$ \\
\hline 11 & $13,7 \mathrm{a}$ & $14,0 \mathrm{a}$ & $12,0 \mathrm{~b}$ & $14,9 \mathrm{a}$ & $14,5 \mathrm{a}$ & $8,3 \mathrm{~b}$ & $16,63 \mathrm{a}$ & $16,5 \mathrm{a}$ & $13,8 \mathrm{a}$ & $13,7 \mathrm{a}$ & $14,1 \mathrm{a}$ \\
\hline 12 & $14,1 \mathrm{a}$ & $14,0 \mathrm{a}$ & $12,6 \mathrm{~b}$ & $15,1 \mathrm{a}$ & $14,2 \mathrm{ab}$ & $7,8 \mathrm{~b}$ & $16,68 \mathrm{a}$ & $17,5 \mathrm{a}$ & $14,2 \mathrm{a}$ & $14,0 \mathrm{a}$ & $13,8 \mathrm{a}$ \\
\hline
\end{tabular}

Médias seguidas da mesma letra na horizontal entre os tratamentos não diferem entre si pelo teste de Tukey $(p<0,05)$. Colocar na tabela acima as quantidades dos fertilizantes utilizados a partir do quarto ano de idade.

Os teores foliares de $\mathrm{N}$ em função das aplicações de N, P, K e Mg do segundo ao décimo segundo anos de idade são apresentados na Figura 2. Mesmo na ausência da adubação nitrogenada $\left(\mathrm{N}_{0}\right)$, o teor de $\mathrm{N}$ mostrou-se dentro da faixa adequada para a cultura (24 a $30 \mathrm{~g} \mathrm{~kg}^{-1}$ ) (UEXKULL et al., 1991). Aos 3, 5 e 6 anos das plantas, houve maiores teores foliares de $\mathrm{N}$ com a aplicação deste nutriente na forma de ureia. A falta de resposta à adubação nitrogenada em alguns anos se deve à contribuição da leguminosa Pueraria phaseoloides no fornecimento de $\mathrm{N}$ visto a sua utilização como cobertura do solo na área estudada. $\mathrm{A}$ contribuição da Pueraria phaseoloides como fornecedora de $\mathrm{N}$ no segundo ano é de $455 \mathrm{~kg} / \mathrm{ha} \mathrm{e}$, no oitavo ano, com a degradação dessa leguminosa em consequência do sombreamento causado pelas palmeiras da palma de óleo, de apenas 31 kg/ha (PEREZ, 1997).

Por outro lado, a adubação fosfatada promoveu maiores teores foliares de $\mathrm{N}$ nas plantas com 2, 3 e 4 anos de idade. Tais resultados corroboram com os verificados na literatura (RODRIGUES, 1993; RODRIGUES et al., 1997). Os referidos autores constataram que os teores de $\mathrm{N}$ na folha 17 variaram em função da nutrição fosfatada e que, na sua ausência, a adubação nitrogenada proporcionou significativa deficiência, mesmo com a aplicação de $1 \mathrm{~kg}$ de ureia/planta. Dentre os vários processos relacionados às funções do $\mathrm{P}$ no metabolismo vegetal, este nutriente fornece energia na forma de ATP para a absorção iônica ativa e síntese proteica, apresentando assim um sinergismo com o $\mathrm{N}$. 
As adubações potássica e magnesiana não influenciaram significativamente nos teores foliares de Dubos et al. (1999) verificaram aumentos na absorção de $N$ por plantas de palma de óleo cultivadas em diferentes regiões com a aplicação de doses de Mg. Vale ressaltar que o teor foliar de $\mathrm{N}$ a partir do 3o ano tendeu a apresentar redução considerável nas plantas, aumentando no decorrer do 4 ao 6 ano, reduzindo expressivamente nas plantas adultas (12 anos). Estes resultados foram semelhantes aos obtidos por Uexkull et al. (1991) que recomendam para plantas de palma de óleo com mais de seis anos de idade a faixa adequada de 24 a $28 \mathrm{~g} \mathrm{~kg}^{-1}$ de N. Por outro lado, segundo Rognon (1984), o nível crítico de $\mathrm{N}$ não pode ser fixo, pois varia em função dos teores de $\mathrm{P}$. Um teor de $25 \mathrm{~g} \mathrm{~kg}^{-1}$ de $\mathrm{N}$ pode conduzir à sua deficiência, se o teor de $\mathrm{P}$ for de $1,7 \mathrm{~g} \mathrm{~kg}^{-1}$, ou a uma boa nutrição se o teor de $\mathrm{P}$ for de $1,4 \mathrm{~g} \mathrm{~kg}^{-1}$.

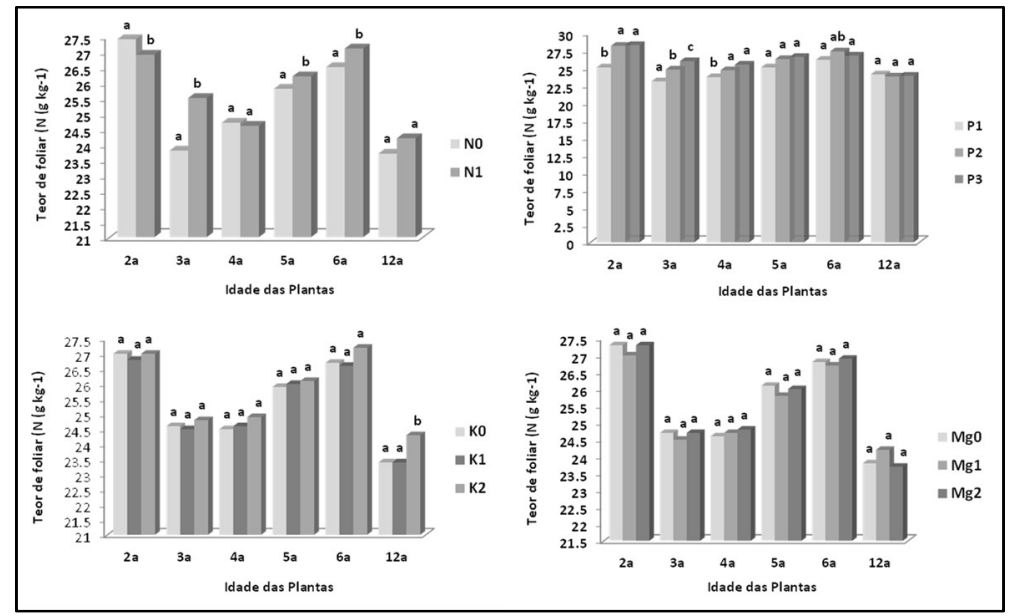

Figura 1: Teores foliares de N na palma de óleo em função da adubação nitrogenada, fosfatada, potássica, magnesiana e da idade das plantas. Letras iguais nas colunas, comparando níveis de adubação em cada idade das plantas, não diferem significativamente pelo teste Tukey $(p<0,05)$.

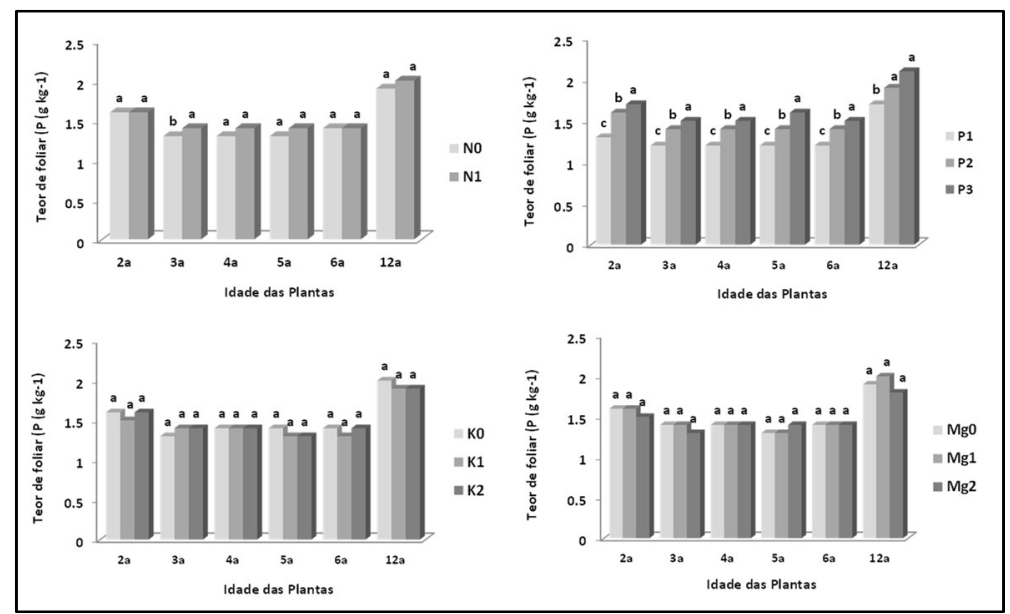

Figura 2: Teores foliares de P na palma de óleo em função da adubação nitrogenada, fosfatada, potássica, magnesiana e da idade das plantas. Letras iguais nas colunas, comparando níveis de adubação em cada idade das plantas, não diferem significativamente pelo teste Tukey $(p<0,05)$.

Os teores foliares de $\mathrm{P}$ na palma de óleo, obtidos no segundo ano (folha 9) e nos demais anos (folha 17), aumentaram, em todos as idades avaliadas, com o aumento das doses de fosfino aplicadas (Figura 2). Os resultados mostram que não ocorreu diminuição nos teores de $\mathrm{P}$ com o envelhecimento das plantas, pois até o sexto ano os teores correspondentes ao nível 3 de $P\left(P_{3} ; 2000\right.$ e $1500 \mathrm{~g} /$ planta) permaneceram semelhantes e, no décimo segundo ano, houve aumento nos mesmos com a menor dose de fosfino $\left(\mathrm{P}_{1} ; 500\right.$ 
$\mathrm{g} /$ planta). A adubação fosfatada, tendo como fonte o fosfino, influenciou nos teores foliares de $\mathrm{P}$, mostrando a dependência das plantas de palma de óleo pelo nutriente. Não foi verificada diferença significativa nos teores foliares de $\mathrm{P}$ com a adubação nitrogenada, exceto no 30 ano. As adubações potássicas e magnesianas também não influenciaram de forma significativa os teores foliares de $\mathrm{P}$ da palma de óleo até os 12 anos de idade.

Com exceção do 3ำ, o teor foliar de K não foi influenciado pelo suprimento de $\mathrm{N}$ (Figura 3). Nas plantas que receberam adubação nitrogenada, houve uma tendência à diminuição dos teores foliares de $K$ com o envelhecimento das mesmas, mostrando a importância deste macronutriente para a cultura da palma de óleo (VIÉGAS, 1993; SANTOS, 1999). As plantas de palma de óleo apresentaram decréscimo significativo nos teores foliares de $K$ com a aplicação das doses de $P\left(P_{1}, P_{2}\right.$ e $\left.P_{3}\right)$ e com o aumento das suas idades. $O$ declínio significativo nos teores foliares de K pela adubação fosfatada ocorreu em razão da interação com o Ca proveniente do fosfino ( 42 \% de $\mathrm{CaO}$ ). O suprimento de $\mathrm{Ca}$ em altas doses pode levar ao antagonismo na absorção do K, uma inibição do tipo competitiva.

$\mathrm{O}$ teor foliar de $\mathrm{K}$ foi mais elevado nas plantas que receberam adubação à base do próprio nutriente. A partir do sexto ano foi necessário aumentar a dose de cloreto de potássio, em função do aumento na expectativa de produção, haja vista a exportação do $\mathrm{K}$ em grandes quantidades pelos cachos (VIÉGAS et al., 2000). A deficiência de K reduz a produção da palma de óleo (Tabela 4), uma vez que compromete a emissão foliar a partir da ocorrência de necrose marginal ao longo dos folíolos, começando pelo ápice. O K é o nutriente mais extraído pela palma de óleo, sendo exportados $78 \mathrm{~kg} / \mathrm{ha}$ de $\mathrm{K}$ na produção de $25 \mathrm{t} / \mathrm{ha}$ de cachos de frutos frescos (GAMARRA, 2014). Com relação ao aumento no suprimento de Mg foi verificado diminuição nos teores foliares de $\mathrm{K}$ das plantas com 6 e 12 anos de idade, provavelmente por um efeito de inibição competitiva entre estes nutrientes nesta fase. Foi verificada diminuição da absorção de $\mathrm{Mg}$ com a elevação de doses de $\mathrm{KCl}$ aplicadas na cultura da palma de óleo (DUBOS et al., 1999).

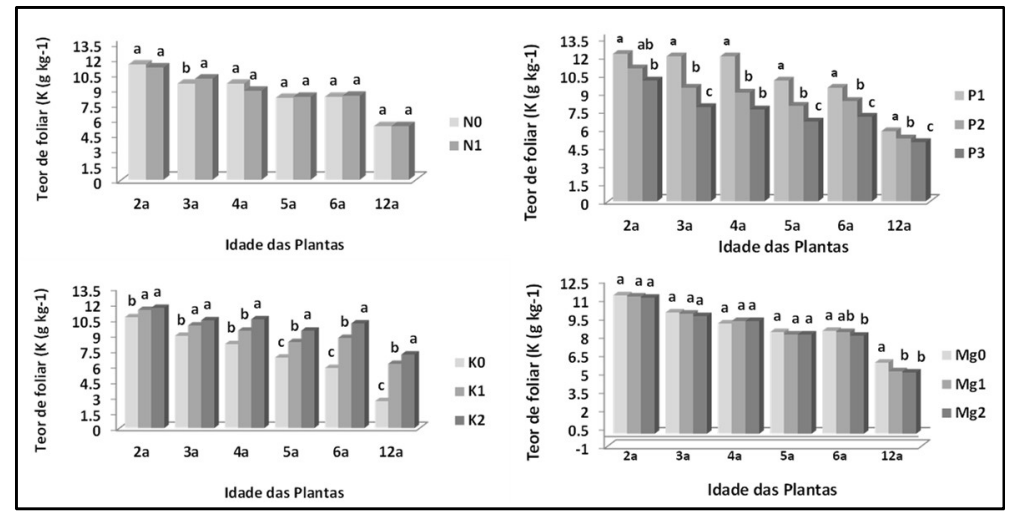

Figura 3: Teores foliares de $\mathrm{K}$ na palma de óleo em função da adubação com N, $\mathrm{P}, \mathrm{K}$ e $\mathrm{Mg}$ e da idade das plantas. Letras iguais nas colunas, comparando níveis de adubação em cada idade das plantas, não diferem significativamente pelo teste Tukey $(p<0,05)$.

A adubação nitrogenada não influenciou os teores foliares de $\mathrm{B}$ e Cl nas plantas de palma de óleo até o 6 o ano de idade (Tabela 5). Por outro lado, observa-se que a adubação fosfatada promoveu aumento significativo nos teores foliares de $\mathrm{B} \mathrm{e} \mathrm{Cl}$. 
Tabela 5: Efeito da adubação com N, P, K e Mg nos teores foliares de B e Cl em função da idade da palma de óleo.

\begin{tabular}{|c|c|c|c|c|c|c|c|c|c|c|c|}
\hline $\begin{array}{l}\text { Idade } \\
\text { (anos) }\end{array}$ & $\mathbf{N}_{0}$ & $\mathbf{N}_{1}$ & $\mathbf{P}_{1}$ & $P_{2}$ & $\mathbf{P}_{3}$ & $\mathrm{~K}_{0}$ & $K_{1}$ & $\mathrm{~K}_{2}$ & $\mathrm{Mg}_{0}$ & $\mathrm{Mg}_{1}$ & $\mathrm{Mg}_{2}$ \\
\hline \multicolumn{12}{|c|}{$B\left(\mathrm{mg} \mathrm{kg}^{-1}\right)$} \\
\hline 3ㅇ ano & $18,68 a$ & $19,25 a$ & $16,34 c$ & $18,31 \mathrm{~b}$ & $21,35 a$ & $20,33 a$ & $18,64 a$ & $17,93 a$ & $19,42 a$ & $19,36 a$ & $18,13 a$ \\
\hline 40 ano & $17,68 a$ & $18,38 a$ & $16,65 b$ & $17,77 a b$ & $19,67 a$ & $20,28 a$ & $17,18 a$ & $16,62 b$ & $18,03 a$ & $18,26 a$ & $17,80 a$ \\
\hline 5o ano & $21,89 a$ & $21,77 a$ & $18,88 \mathrm{c}$ & $21,33 \mathrm{~b}$ & $25,28 a$ & $23,78 a$ & $21,54 b$ & $20,17 c$ & $21,77 a$ & $21,82 a$ & $22,00 a$ \\
\hline 60 ano & $22,32 a$ & $21,70 a$ & $20,08 b$ & $21,99 a b$ & $23,96 a$ & $27,81 a$ & $19,81 b$ & $18,41 b$ & $23,78 a$ & $21,69 a b$ & $20,55 b$ \\
\hline $12^{\circ}$ ano & $19,77 a$ & $18,49 a$ & $16,92 b$ & $19,60 \mathrm{ab}$ & $20,87 a$ & $21,22 a b$ & $19,22 \mathrm{ab}$ & $16,93 b$ & $250,28 a$ & $18,64 a$ & $18,47 a$ \\
\hline \multicolumn{12}{|c|}{$\mathrm{Cl}\left(\mathrm{g} \mathrm{kg}^{-1}\right)$} \\
\hline 20 ano & $0,54 a$ & $0,52 b$ & $0,51 b$ & $0,54 b$ & $0,55 a$ & $0,36 c$ & $0,60 \mathrm{a}$ & $0,65 a$ & $0,53 a$ & $0,52 a$ & $0,54 a$ \\
\hline 3ㅇ ano & $0,50 a$ & $0,49 a$ & $0,44 b$ & $0,50 a b$ & $0,55 a$ & $0,33 b$ & $0,56 a$ & $0,59 a$ & $0,48 a$ & $0,48 a$ & $0,52 a$ \\
\hline 40 ano & $0,51 a$ & $0,52 a$ & $0,45 c$ & $0,52 b$ & $0,57 a$ & $0,37 b$ & $0,57 a$ & $0,60 a$ & $0,51 a$ & $0,50 a$ & $0,53 a$ \\
\hline 5o ano & $0,48 a$ & $0,49 a$ & $0,42 b$ & $0,47 b$ & $0,54 a$ & $0,35 b$ & $0,52 a$ & $0,56 a$ & $0,46 a$ & $0,48 a$ & $0,49 a$ \\
\hline 60 ano & $0,55 a$ & $0,56 a$ & $0,47 c$ & $0,54 b$ & $0,64 a$ & $0,44 b$ & $0,58 a$ & $0,62 a$ & $0,53 a$ & $0,55 a$ & $0,56 a$ \\
\hline
\end{tabular}

Médias seguidas da mesma letra na horizontal entre os tratamentos não diferem entre si pelo teste de Tukey ao nível de $5 \%$ de probabilidade.

Os teores foliares de B estão na faixa considerada adequada (15 a $25 \mathrm{mg} \mathrm{kg}^{-1}$ de B) (UEXKULL et al., 1991), em relação à adubação fosfatada, mesmo na ausência desta adubação no terceiro e quarto ano, mostrando assim uma estreita relação entre o Ca contido no fosfino e o B. Os teores foliares de Cl (Figura 4a) variaram entre 4,7 e 6,4 $\mathrm{g} \mathrm{kg}^{-1}$ de Cl, no quinto e sexto ano, respectivamente, e estão dentro da faixa ótima de 4,5 a 6,0 $\mathrm{g} \mathrm{kg}^{-1}$ de $\mathrm{Cl}$ (UEXKULL et al., 1991). Em contraste à adubação fosfatada (Figura 5a), os teores foliares de B diminuíram com a aplicação de cloreto de potássio (Figura 5b). A cultura da palma de óleo tem alta demanda por $\mathrm{K}$, porém elevando as taxas do adubo potássico induz ou se acentua a deficiência em B, recomendando a aplicação conjunta dos dois adubos, principalmente nos solos ácidos tropicais, pobres em matéria orgânica, principal fonte de B no solo. Essa redução na disponibilidade de B, como consequência da adubação potássica, é uma das causas para a ocorrência da deficiência desse micronutriente em plantas de palma de óleo na Amazônia.

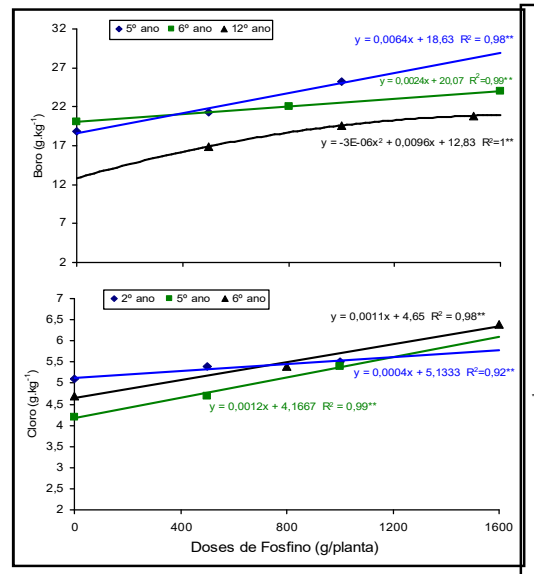

(a)

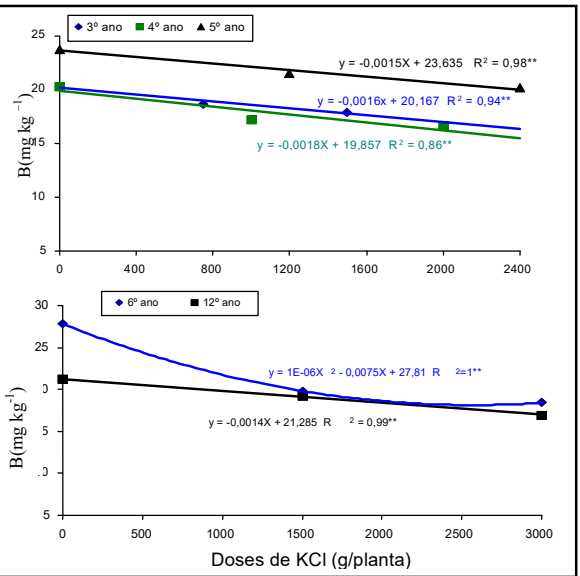

(b)

Figura 4: Efeito da adubação fosfatada sobre o teor de $\mathrm{Cl}$ na folha 17 (a) e efeito da adubação potássica sobre o teor de $B$ na folha 9 ( 2 ono) (b) em plantas de palma de óleo.

Houve aumento no teor foliar de $\mathrm{Cl}$ em relação à adubação fosfatada (Figura 5a), fato este explicado pelo sinergismo entre Ca e Cl (MALAVOLTA, 2006) e concordam com os resultados obtidos por Taffin et al. (1980) em estudos realizados na África, sobre as relações Cl e K - Ca na palma de óleo e com os obtidos por Pacheco et al. (1985). Os teores foliares de $\mathrm{Cl}$ variaram entre 4,7 e $6,4 \mathrm{~g} \mathrm{~kg}^{-1} \mathrm{de} \mathrm{Cl}$, no quinto e sexto ano, 
respectivamente, e estão dentro da faixa ótima (4,5 a 6,0 $\mathrm{g} \mathrm{kg}^{-1}$ de Cl) (UEXKULL et al., 1991). Em contraste à adubação fosfatada, os teores foliares de B diminuíram com a aplicação de cloreto de potássio (Figura 4b), comportamento semelhante foi observado por Lins (1982) na cultura do coqueiro. A adubação potássica reduziu o teor foliar de B, elevando a sua deficiência pelas plantas.

Na Figura 5, a partir da Análise de Componentes Principais (PCA), verificamos as relações de dependências e, ou, as interações entre os teores dos nutrientes nas folhas em relação às idades das plantas. A Figura 5a apresenta as interações entre as idades das plantas e os macronutrientes nos teores foliares de $\mathrm{N}$ das plantas, em que a adubação nitrogenada em nível $\mathrm{N}_{0}$ e a fosfatada em nível $\mathrm{P}_{2}$ apresentaram forte correlação ao favorecer a concentração foliar de $\mathrm{N}$ no 20 ano. A adubação à base de fosfino $\left(33 \%\right.$ de $\left.\mathrm{P}_{2} \mathrm{O}_{5}\right)$ no nível $\mathrm{P}_{1}$ indicou resposta nos teores foliares de $\mathrm{N}$ em plantas com idade de 12 anos. $\mathrm{O}$ teor foliar em plantas de 3 anos foi fortemente influenciado pela adubação nitrogenada $\left(N_{1}\right)$ e fosfatada $\left(P_{3}\right)$. Os níveis de adubação favoreceram o teor foliar nas plantas em idade de 4 anos e 6 anos.

Para o efeito da adubação com N, P, K e Mg sobre o teor foliar de P (Figura 6b), pode-se observar a formação de alguns grupos similares quanto à resposta do $P$. Os níveis adotados de fosfino $\left(P_{1}\right)$ favoreceram o teor foliar de $\mathrm{P}$ nas plantas com idade de 4 anos. Por outro lado, a dose de fosfino de $1000 \mathrm{~g} / \mathrm{planta}\left(\mathrm{P}_{3}\right)$ e a magnesiana de $1000 \mathrm{~g} /$ planta $\left(\mathrm{Mg}_{2}\right)$ favoreceram o teor foliar de $\mathrm{P}$ em plantas com 5 anos. A ausência da adubação magnesiana $\left(\mathrm{Mg}_{0}\right)$ e a dose de $500 \mathrm{~g} /$ planta $\left(\mathrm{Mg}_{1}\right)$, além da adubação potássica de $1500 \mathrm{~g} /$ planta $\left(\mathrm{K}_{2}\right)$, otimizaram o teor foliar de $\mathrm{P}$ nas plantas mais velhas (12 anos). Plantas jovens ( 3 anos) apresentaram teores foliares de $\mathrm{P}$ fortemente relacionados aos níveis de $\mathrm{K}\left(\mathrm{K}_{1}\right)$. Apesar das produções nas doses de $\mathrm{P}_{3}(2000$ e $1500 \mathrm{~g} /$ planta) serem superiores às de $P_{2}$ (1250 e $1000 \mathrm{~g} /$ planta) não houve diferença significativa, com exceção do décimo primeiro e décimo segundo ano.

$\mathrm{O}$ teor foliar de $\mathrm{K}$ (Figura 5c) em plantas com 6 anos foi fortemente correlacionado com os níveis de $P\left(P_{2}\right)$, cloreto de potássio $\left(K_{1}\right)$ e ausência de magnésio $\left(\mathrm{Mg}_{0}\right)$. Plantas de 3, 4 e 5 anos apresentaram forte correlação, sem adubação fosfatada $\left(\mathrm{P}_{1}\right)$, no teor foliar de K.-O teor foliar de Ca (Figura $5 \mathrm{~d}$ ), a partir dos níveis de adubação ( $N, P, K$ e Mg), foi fortemente correlacionado com os níveis de sulfato de $\mathrm{Mg}\left(\mathrm{Mg}_{2}\right)$ nas plantas de 3, 4 e 5 anos. Plantas jovens ( 2 anos) apresentaram teor foliar de Ca com forte correlação com cloreto de $\mathrm{K}\left(\mathrm{K}_{2}\right)$. Por outro lado, os teores de Ca nas folhas da palma de óleo de 12 anos se correlacionaram com as doses de fosfino $\left(P_{1}\right)$.

Os teores foliares de $\mathrm{Mg}$, a partir dos níveis de adubação ( $\mathrm{N}, \mathrm{P}, \mathrm{K}$ e Mg), nas plantas com 6 anos de idade foram significativamente inter-relacionados com aplicação de sulfato de $\mathrm{Mg}\left(\mathrm{Mg}_{1}\right)$, ureia $\left(\mathrm{N}_{1}\right)$ e fosfino (Figura 5e). Plantas adultas de palma de óleo aumentaram os seus teores foliares de $\mathrm{Mg}$ com a aplicação de doses deste nutriente em diferentes regiões da América Latina, África e Ásia (DUBOS et al., 1999). Foi verificado o aumento dos teores foliares de $\mathrm{Mg}$ em palma de óleo com o aumento da porcentagem de saturação de Mg no solo. Plantas jovens (2 e 4 anos) apresentaram teor foliar de $\mathrm{Mg}$ com forte correlação com nível de cloreto de $\mathrm{K}\left(\mathrm{K}_{1}\right.$ e $\left.\mathrm{K}_{2}\right)$. $\mathrm{O}$ teor foliar de $\mathrm{S}$ (Figura $5 f$ ) nas plantas de 2 e 5 anos respondeu significativamente à adubação de fosfino e cloreto de $\mathrm{K}\left(\mathrm{K}_{1}\right)$. A adubação fosfatada $\left(\mathrm{P}_{3}\right)$ em plantas de 3 anos foi influenciada pela aplicação de ureia $\left(\mathrm{N}_{1}\right)$. Em plantas mais velhas (12 anos), o teor foliar de $S$ foi 
correlacionado com a aplicação de sulfato de $\mathrm{Mg}(13 \%$ de $\mathrm{S})\left(\mathrm{Mg}_{2}\right)$ e de fosfino $\left(\mathrm{P}_{1}\right)$.
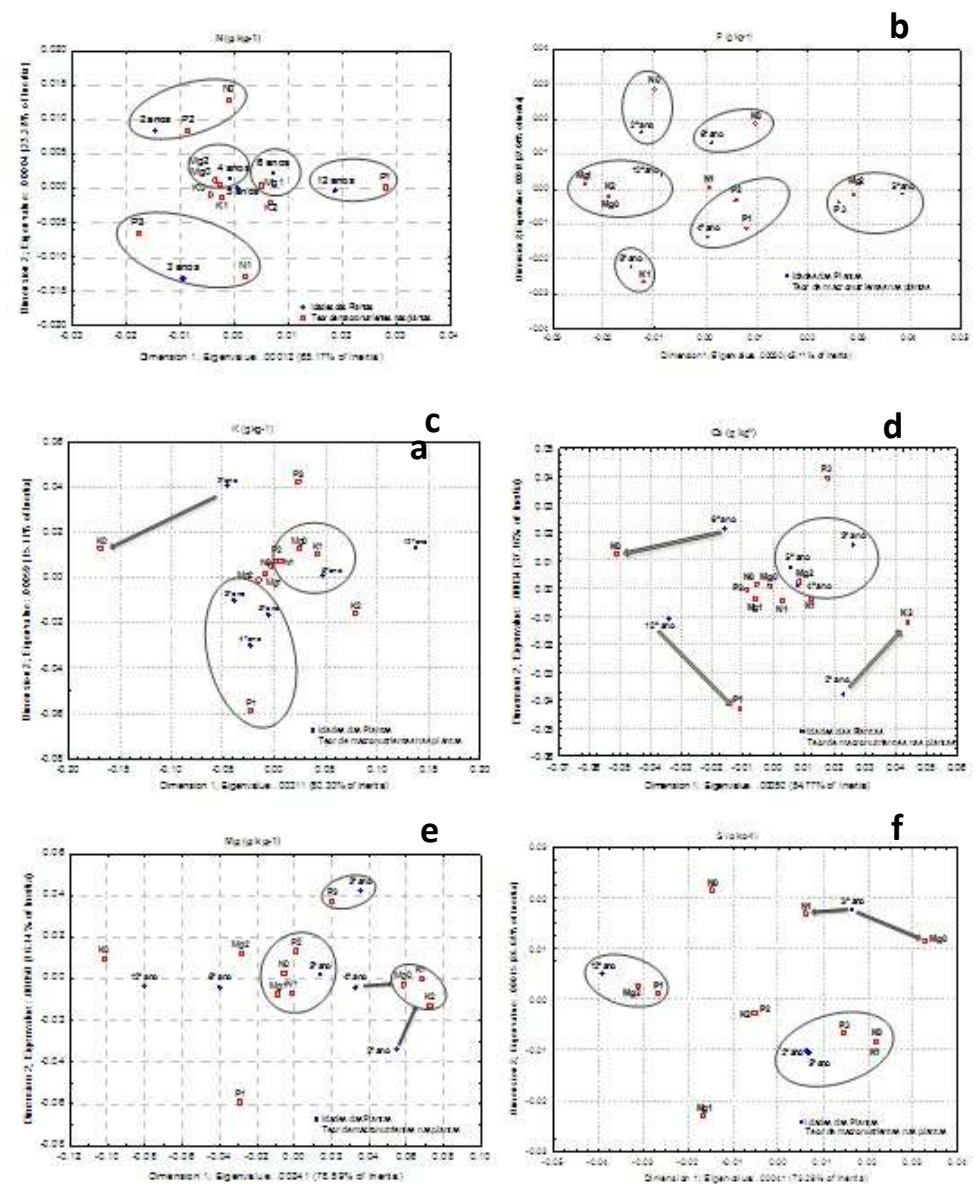

Figura 5: Análise de componentes principais (ACP) na avaliação dos teores foliares da palma de óleo em relação à idade das plantas e aos níveis de adubação com macronutrientes: (a) nível de adubação nitrogenada, (b) nível de adubação fosfatada, (c) nível de adubação potássica, (d) nível de adubação fosfatada, (e) nível de adubação magnesiana e (f) nível de adubação enxofre.

\section{CONCLUSÕES}

A palma de óleo não responde de forma significativa à aplicação de $\mathrm{N}$, na forma de ureia, no aumento na produção, quando da utilização da Pueraria phaseoloides como planta de cobertura do solo, assim como a aplicação de magnésio na forma de sulfato de magnésio. A adubação fosfatada, na forma de fosfino, é uma fonte viável para promover aumentos na produção e para uma correta nutrição mineral da palma de óleo; A adubação fosfatada e potássica de forma equilibrada tende a elevar a produção da palma de óleo; $\mathrm{A}$ adubação fosfatada promove a elevação dos teores foliares de $\mathrm{Cl}$, e a adubação com $\mathrm{KCl}$ diminuiu os teores foliares de B.

\section{REFERÊNCIAS}

BAKAR, R.; DARUS, S. Z.; KULASEHASAN, S.. Effects of ten year application of empty fruit bunches in an oil palm plantation on soil chemical properties. Nutrient Cycling in Agroecosystems, Dordrecht, v.89, n.3, p.341-349, 2011. DOI: http://doi.org/10.1007/s10705-010-9398-9

DUBOS, B.; CALIMAN, J. P.; CORRADO, F.; QUENCEZ, P.; SISWO, S.; TAILLIEZ, B.. Rôle de la nutrition en magnésium chez le palmier à huile. Plantations, Recherche, Developpement, v.6, n.5, p.313-325, 1999.
GAMARRA, Y. P. L.. Modelo de recomendação de adubação e calagem para a cultura de dendê (Elaeis guineensis jacq.) com base em balanço nutricional. Dissertação (Mestrado em Solos e Nutrição de Plantas) - Universidade Federal de Viçosa, Viçosa, 2014.

GUZMÁN, C. P. H.. Teores referenciais de nutrientes em folhas de dendê (Elaeis guineensis. Jacq) para as condições da Amazônia. Dissertação (Mestrado em Solos e Nutrição de 
Plantas) - Universidade Federal de Viçosa, Viçosa, 2014.

IRHO. Institut De Recherches Pour Les Huiles Et Oléagineux. Rapport d'activite. Oléagineux. 44 ed. 1989.

LINS, P. M. P.. Resposta do coqueiro (Cocos nucifera) à aplicação de N, P, K e Mg nas condições edafoclimáticas de Mojú/PA. Dissertação (Mestrado) - Faculdade de Ciências Agrárias do Pará, Belém, 2000.

MALAVOLTA, E.. Manual de nutrição mineral de plantas. São Paulo: Agronômica Ceres, 2006.

PACHECO, A. R.; TALLIEZ, B. J.; ROCHA, R. L.; LIMA, E. J.. Les deficiences minérales du palmier a huile ( $E$. guineensis Jacq.) dans la région de Belém, Pará (Brésil). Oléagineux, Paris, v.40, n.6, p.296-305, 1985.

PEREZ, P. N. L.. Crescimento, concentração e conteúdo de nutrientes em Pueraria phaseoloides $\mathrm{L}$. com dois anos a oito anos de idade em Latossolo Amarelo distrófico, Tailândia, Pará. Dissertação (Mestrado) - Faculdade de Ciências Agrárias do Pará, Belém, 1997.

PHOSRI, C.; RODRIGUEZ, A.; SANDRES, I. R.; JEFFRIES, P.. The role of mycorrhizas in more sustainable oil palm cultivation. Agriculture, Ecosystems and Environment, n.135, p.187193, 2010.

RODRIGUES, M. R. L.. Resposta do dendezeiro (Elaeis guineensis Jacq.) à aplicação de fertilizantes nas condições do médio Amazonas. Dissertação (Mestrado) - Universidade de São Paulo, Piracicaba, 1993.

RODRIGUES, M. R. L.; MALAVOLTA, E.; CHAILLARD, H.. La fumure du palmier à huile em Amazonie centrale brésilienne. Plantations, Recherche, Development, v.4, p.392-400, 1997.

ROGNON, F.. Palmier à huile. In: PREVEL, P. M.; GAGNNARD, J.; GAUTIER, P. Analyse vegetable dans controle de
I'alimentation des plantes. Paris: Technique et Documentation Lavosier, 1984. p.426-446.

SARRUGE, J. R.; HAAG, H. P.. Análises químicas em plantas. Dissertação (Mestrado em Química) - Universidade de São Paulo, Piracicaba, 1974.

SANTOS, L. D.. Resposta do dendezeiro (Elaeis guineensis Jacq) à aplicação de $\mathrm{P} \mathrm{K}$ e Mg nas condições edafoclimáticas de Tailândia - Pará. Dissertação (Mestrado) - Faculdade de Ciências Agrárias do Pará, Belém, 1999.

SCHROTH, G.; RODRIGUES, M. R. L.; D'ANGELO, S. A.. Spatial patterns of nitrogen mineralization, fertilizer distribution and roots explain nitrate leaching from mature Amazonian oil palm plantation. Soil Use and Management, v.16, p.222229, 2000.

SILVA, F. L; HOMMA, A. K. O.; PENA, H. W. A.. O cultivo do dendezeiro na Amazônia: promessa de um novo ciclo econômico na região. Observatório de la Economia Latinoamericana, 2011.

TAFFIN, G.; QUENCEZ, P.. Aspect de la nutrition anionique chez le palmiere à huile et le cocotier. Probleme du chlore. Oléagineux, Paris, v.32, n.12, p.539-544, 1980.

UEXKULL, H. R. V.; FAIRHUST, T. H.. Fertilizing for high yield and quality: The oil palm. Bern: International Potash Institute. 1991.

VIÉGAS, I. J. M.. Crescimento do dendezeiro (Elaeis guineensis Jacq.), concentração, conteúdo e exportação de nutrientes nas partes de plantas com $\mathbf{2}$ a 8 anos de idade, cultivadas em Latossolo Amarelo distrófico, Tailândia-Pará. Tese (Doutorado) - Piracicaba, 1993.

VIÉGAS, I. J. M.; BOTELHO, S. M.. Nutrição e adubação do dendezeiro. In: VIÉGAS, I. J. M.; MÜLLER, A. A.. A cultura do dendezeiro na Amazônia brasileira. Belém: EMBRAPA Amazônia Oriental, 2000.

A CBPC - Companhia Brasileira de Produção Científica (CNPJ: 11.221.422/0001-03) detém os direitos materiais desta publicação. Os direitos referem-se à publicação do trabalho em qualquer parte do mundo, incluindo os direitos às renovações, expansões e disseminações da contribuição, bem como outros direitos subsidiários. Todos os trabalhos publicados eletronicamente poderão posteriormente ser publicados em coletâneas impressas sob coordenação da Sustenere Publishing, da Companhia Brasileira de Produção Científica e seus parceiros autorizados. Os (as) autores (as) preservam os direitos autorais, mas não têm permissão para a publicação da contribuição em outro meio, impresso ou digital, em português ou em tradução. 